\title{
Iliac crest trabecular bone mass and structure in patients with non-steroid treated rheumatoid arthritis
}

\author{
R W E MELLISH,${ }^{1}$ M M O'SULLIVAN,${ }^{2} \mathrm{~N}$ J GARRAHAN,${ }^{1}$ AND \\ J E COMPSTON ${ }^{1}$
}

From the ${ }^{1}$ Department of Pathology, University of Wales College of Medicine; and the ${ }^{2}$ Department of $\vec{\circ}$ Rheumatology, University Hospital of Wales, Heath Park, Cardiff

SUMMARY Iliac crest trabecular bone volume and structure have been studied in bone biopsy $\vec{\circ}$ specimens from 48 patients with classical or definite rheumatoid arthritis, none of whom had $\rightleftarrows$ received steroids. Results were compared with those obtained from healthy controls matched for $\vec{\infty}^{\circ}$ age and sex. The mean trabecular bone volume in female patients aged 34-50 years was $\mathscr{E}^{\infty}$ significantly lower than in controls $(\mathrm{p}<0 \cdot 01)$; in male patients aged 34-50 years values were also 은 lower than those in controls (mean (SD) $17 \cdot 8(3.2) \vee 22.4(5.6) \%$ total medullary volume), though this difference was not statistically significant. Values in older patients were similar to those of controls. The mean trabecular plate thickness was significantly lower in female patients in all three age groups when compared with the controls $(p<0.005,0 \cdot 05$, and 0.005$)$. Similar but non-significant changes were seen in male patients. The mean trabecular plate density, an index of trabecular number, and the mean trabecular plate separation showed no age related change i either male or female patients, in contrast with the female control group, in whom the mear. trabecular plate density decreased and separation increased with age. These results suggest tha् non-steroid treated rheumatoid arthritis is associated with premature bone loss, the structural basis of which is trabecular thinning.

Key words: bone volume, bone structure.

Several reports have indicated that the prevalence of generalised osteoporosis is increased in patients with rheumatoid arthritis, ${ }^{1-6}$ though it is unclear whether this is attributable to factors such as steroid therapy ${ }^{3478}$ and inactivity ${ }^{410}$ or to the disease process itself. The most important clinical consequence of osteoporosis is fracture, particularly of the vertebrae, femoral neck, and radius; there is some evidence that the incidence of these fractures is increased in patients with rheumatoid arthritis. ${ }^{11} 12$

The structural basis of bone loss at a microanatomical level may have important implications with regard to bone strength and hence the likelihood of fracture. If bone loss occurs by trabecular thinning, with preservation of the trabecular architecture, bone strength may be less adversely affected than if the mechanism of bone loss is by erosion and removal of trabeculae, resulting in loss of intercon-

Accepted for publication 21 May 1987.

Correspondence to Dr J E Compston, Department of Pathology, University of Walcs College of Medicine. Heath Park. Cardiff CF4 4XN. nection of the trabecular bone. ${ }^{13}$ One approach to the study of bone microanatomical structure is to measure the mean trabecular plate thickness (MTPT); from this the mean trabecular plate? separation (MTPS) and density (MTPD) can be $\frac{5}{3}$ calculated. ${ }^{14}$ If bone loss is due to trabecular thinning the MTPT will be reduced, whereas the MTPS and MTPD will remain unchanged. Conversely, if bone loss by erosion predominates, $\frac{\text { 의 }}{5}$ MTPT will show little change while the MTPS will increase and the MTPD will decrease. In this study we have investigated trabecular bone mass in iliac No crest biopsy specimens from 48 patients with chronic rheumatoid arthritis and have used the approach $\mathrm{N}^{-}$ outlined above to study changes in bone micro- $\omega$ anatomical structure. To exclude steroid induced effects on bone only patients who had not receivedo any systemic steroid therapy were studied.

Patients and methods

Forty eight patients with definite or classical rheumatoid arthritis, ${ }^{15}$ who had been enrolled into a trial 
of second line therapy, were studied. Thirty three were female, and the mean age of all patients was 53 years (range $34-71$ ). The median duration of disease was four years (range 1-25). None had received systemic steroid therapy at any time, though a few had been given intra-articular steroids. No patient was receiving vitamin $D$ or calcium therapy. Most patients were taking one or more of a variety of non-steroidal anti-inflammatory drugs; in addition, all were receiving second line therapy consisting of one of the following: penicillamine (maximum $500 \mathrm{mg} /$ day) $(\mathrm{n}=18)$, hydroxychloroquine $(400 \mathrm{mg} /$ day $)(\mathrm{n}=10)$, and auranofin $(6 \mathrm{mg}$ daily) or intramuscular sodium aurothiomalate $(50 \mathrm{mg} / \mathrm{month})$ maintenance $(\mathrm{n}=20)$.

Patients who were housebound or restricted to a wheelchair were excluded from the study, as were those with a history of gastrointestinal disease or surgery, liver disease, chronic renal disease, endocrine disease, or known metabolic bone disease. Informed written consent was obtained from each patient and permission for the study was granted by the local ethical committee. Disability was assessed by the Steinbroker ${ }^{16}$ and the London ${ }^{17}$ methods.

\section{CONTROLS}

Control values for the indices measured in bone were obtained from age and sex matched control subjects, who underwent bone biopsy while under general anaesthetic for a minor surgical procedure. Details of these subjects have been published elsewhere. ${ }^{18}$

For the purpose of analysis the patients and controls were divided into age groups, three for the women (34-50, 50-60, and 60-80 years) and two for the men (34-50 and 50-80 years).

\section{B O NE BIOPSY}

Transiliac bone biopsy specimens were obtained one inch below and behind the left anterior superior iliac spine using a 6 or $8 \mathrm{~mm}$ internal diameter trephine. Undecalcified sections $(8 \mu \mathrm{m})$ were stained by the von Kossa technique using a van Gieson counterstain. All measurement was made with an IBAS II image analyser (Kontron, West Germany).

The following indices were obtained by measurement or calculation:

Trabecular bone volume (TBV; \% total medullary volume). The total amount of mineralised and unmineralised bone, expressed as a percentage of the total medullary volume, was measured in a minimum of 40 fields from three or more sections at a magnification of $\times 207$.

Mean trabecular plate thickness (MTPT; $\mu \mathrm{m}$ ). This was measured by a computerised technique using the IBAS II image analyser. Details of the method have been reported elsewhere. ${ }^{19}$ The bone section was viewed with a television camera and microscope at a magnification of $\times 83$. All fields from six sections were examined from each biopsy specimen. After the image had been edited using the digitising tablet and cursor it was converted to a binary image. This was then simplified by skeletonisation to provide the symmetrical axis of the original bone profile. Circles were then generated along the trabeculae from sample points spaced 20 pixels apart; when the circle was tangential to two opposing boundaries at the same time the diameter of that circle was taken to be the width of the trabecula at that point. The trabecular width at the nodes or junctions were included in the measurement of MTPT. Apart from the image editing, the method was completely automatic and had a high reproducibility (coefficient of variation for repeated measurements $2 \cdot 8 \%$ ).

Mean trabecular plate separation (MTPS; $\mu \mathrm{m}$ ). This is an index of the distance between trabecular plates and is calculated as follows ${ }^{14}$ :

$$
\text { MTPS=MTPT } \frac{(100)}{(T B V-1)}
$$

The calculation is based on the assumption that the plates are parallel, and the value obtained represents the shortest distance between the plates.

Mean trabecular plate density. This provides an index of trabecular plate number and is calculated as follows ${ }^{14}$ :

$$
\mathrm{MTPD}=\operatorname{TBV}(\%) \times \frac{10}{\mathrm{MTPT}}
$$

\section{STATISTICS}

Correlations between bone histomorphometric indices and continuous clinical variables were ex-

Table 1 Clinical details of patients

\begin{tabular}{lc}
\hline Number & 48 \\
Age (years) & $53 \cdot 3(8 \cdot 9)^{*}$ \\
Duration of disease (years) & $4 \cdot 0 \dagger$ \\
Percentage with erosive disease & $93 \cdot 9$ \\
Percentage with positive rheumatoid factor & $85 \cdot 7$ \\
Steinbroker assessment (\%) & \\
Class 1 & $14 \cdot 3$ \\
Class 2 & $65 \cdot 3$ \\
Class 3 & $20 \cdot 4$ \\
Class 4 & 0 \\
London score & $1 \cdot 26(0 \cdot 71)^{*}$ \\
\hline
\end{tabular}

*Mean (SD).

†Median. 
832 Mellish, O'Sullivan, Garrahan, Compston

Table 2 Bone histomorphometric data for the women*

\begin{tabular}{|c|c|c|c|c|c|c|c|c|c|}
\hline & \multicolumn{3}{|c|}{ Group 1 (34-50 years) } & \multicolumn{3}{|c|}{ Group $2(50-60$ years $)$} & \multicolumn{3}{|c|}{ Group $3(60-80$ years $)$} \\
\hline & $\begin{array}{l}R A \\
(n=9)\end{array}$ & $\begin{array}{l}\text { Control } \\
(n=9)\end{array}$ & $\begin{array}{l}p \\
\text { Value }\end{array}$ & $\begin{array}{l}R A \\
(n=14)\end{array}$ & $\begin{array}{l}\text { Control } \\
(n=10)\end{array}$ & $\begin{array}{l}p \\
\text { Value }\end{array}$ & $\begin{array}{l}R A \\
(n=10)\end{array}$ & $\begin{array}{l}\text { Control } \\
(n=5)\end{array}$ & $\stackrel{p}{\text { Value }}$ \\
\hline TBV $(\%)$ & $19 \cdot 1(5 \cdot 7)$ & $26.9(3.9)$ & $<0 \cdot 01$ & $18 \cdot 3(3 \cdot 4)$ & $22 \cdot 2(5 \cdot 4)$ & NS & $17 \cdot 6(3 \cdot 6)$ & $14 \cdot 7(3 \cdot 2)$ & NS \\
\hline MTPT $(\mu \mathrm{m})$ & $125 \cdot 6(21 \cdot 1)$ & $181.9(32 \cdot 0)$ & $<0.005$ & $121 \cdot 8(19 \cdot 0)$ & $144.3(11.9)$ & $<0.05$ & $123 \cdot 7(16 \cdot 1)$ & $147.8(9.4)$ & $<0.005$ \\
\hline MTPS $(\mu \mathrm{m})$ & $743 \cdot 1(214)$ & $722 \cdot 3(133)$ & NS & $721 \cdot 2(124)$ & $819 \cdot 2(180)$ & NS & $762.6(127)$ & $1137.6(318)$ & NS \\
\hline MTPD $(/ \mathrm{mm})$ & $1.52(0.37)$ & $1.48(0.22)$ & NS & $1.51(0.28)$ & $1.34(0.27)$ & NS & $1.43(0.23)$ & $0.99(0.21)$ & $<0 \cdot(0) 1$ \\
\hline
\end{tabular}

${ }^{*}$ Values are mean $(\mathrm{SD})$.

Table 3 Bone histomorphometric data for the men*

\begin{tabular}{|c|c|c|c|c|c|c|}
\hline & \multicolumn{3}{|c|}{ Group 1 (34-50 years) } & \multicolumn{3}{|c|}{ Group 2 (50-80 years) } \\
\hline & $\begin{array}{l}R A \\
(n=7)\end{array}$ & $\begin{array}{l}\text { Control } \\
(n=5)\end{array}$ & $\begin{array}{l}p \\
\text { Value }\end{array}$ & $\begin{array}{l}R A \\
(n=8)\end{array}$ & $\begin{array}{l}\text { Control } \\
(n=13)\end{array}$ & p Value \\
\hline TBV (\%) & $17 \cdot 8(3 \cdot 2)$ & $22 \cdot 4(5 \cdot 6)$ & NS & $18 \cdot 7(6 \cdot 4)$ & $18 \cdot 3(4 \cdot 9)$ & NS \\
\hline MTPT $(\mu \mathrm{m})$ & $141 \cdot 3(26 \cdot 5)$ & $181 \cdot 6(41 \cdot 3)$ & NS & $154 \cdot 0(41 \cdot 2)$ & $150 \cdot 6(19 \cdot 8)$ & NS \\
\hline MTPS $(\mu \mathrm{m})$ & $851 \cdot 1(142)$ & $857 \cdot 2(113)$ & NS & $901 \cdot 7(128)$ & $915 \cdot 3(204)$ & NS \\
\hline MTPD (/mm) & $1.27(0 \cdot 18)$ & $1 \cdot 24(0 \cdot 16)$ & NS & $1 \cdot 20(0 \cdot 16)$ & $1 \cdot 21(0 \cdot 26)$ & NS \\
\hline
\end{tabular}

${ }^{*}$ Values are mean (SD).

amined by linear regression analysis. Relationships between bone histomorphometric indices and noncontinuous clinical data were examined by two tailed Student's $t$ tests and one way analysis of variance.

\section{Results}

Clinical details and bone histomorphometric data are shown in Tables 1-3 and Figs 1-4. The trabecular bone volume for women in the youngest age group (34-50 years) was significantly lower than is age and sex matched controls $(p<0 \cdot 01)$; there was no significant difference between female patients and controls in either of the other age groups. For men the trabecular bone volume was also lower in patients than controls in the 34-50 year age group, $\stackrel{\mathbb{Q}}{\Omega}$ though this difference did not achieve statistical significance. Values in the older age group were similar in patients and controls.

Significantly lower values for MTPT were found

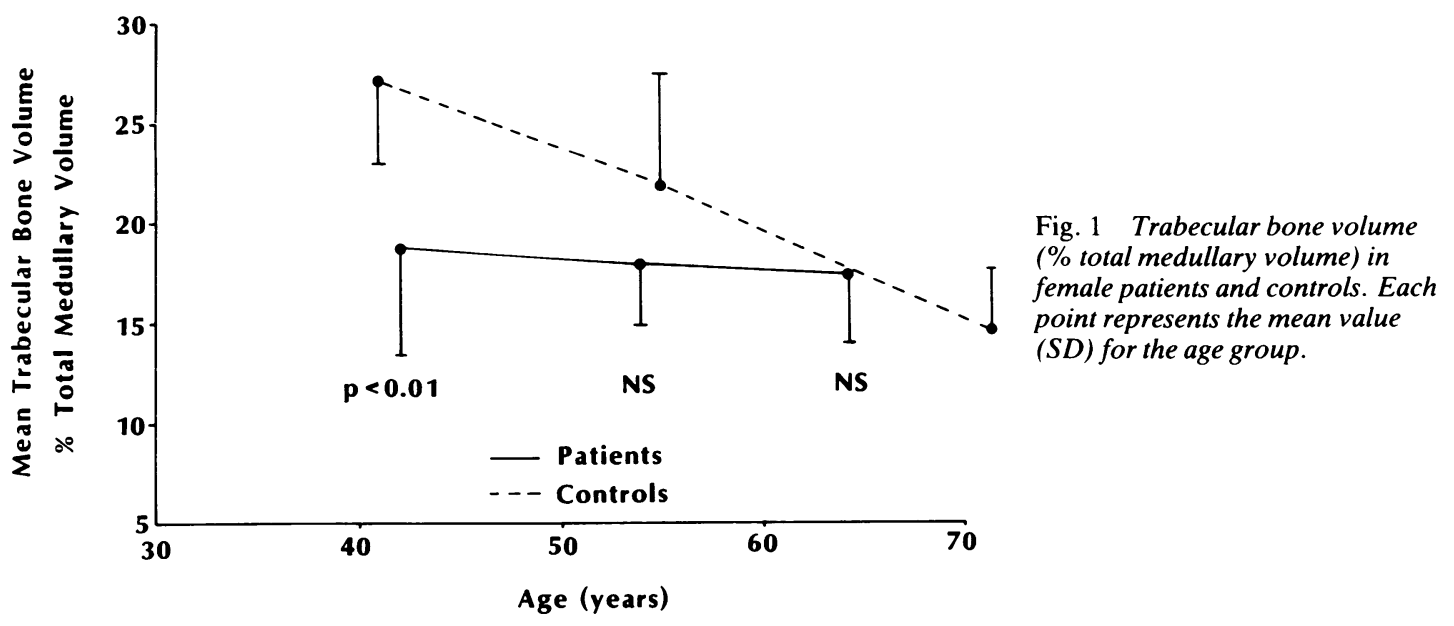

Fig. 1 Trabecular bone volume \% total medullary volume) in point represents the mean value (SD) for the age group. 


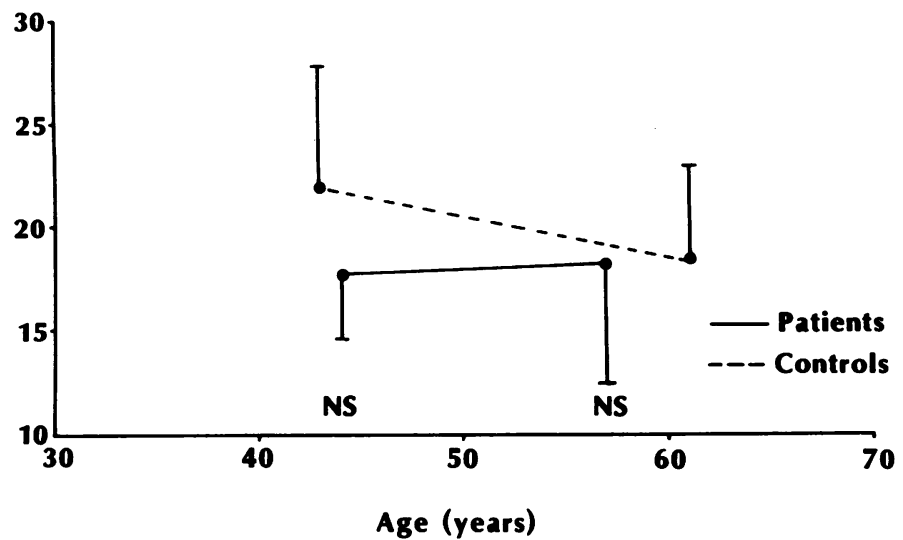

Fig. 2 Trabecular bone volume (\% total medullary volume) in male patients and controls. Each point represents the mean value (SD) for the age group.

Age (years)
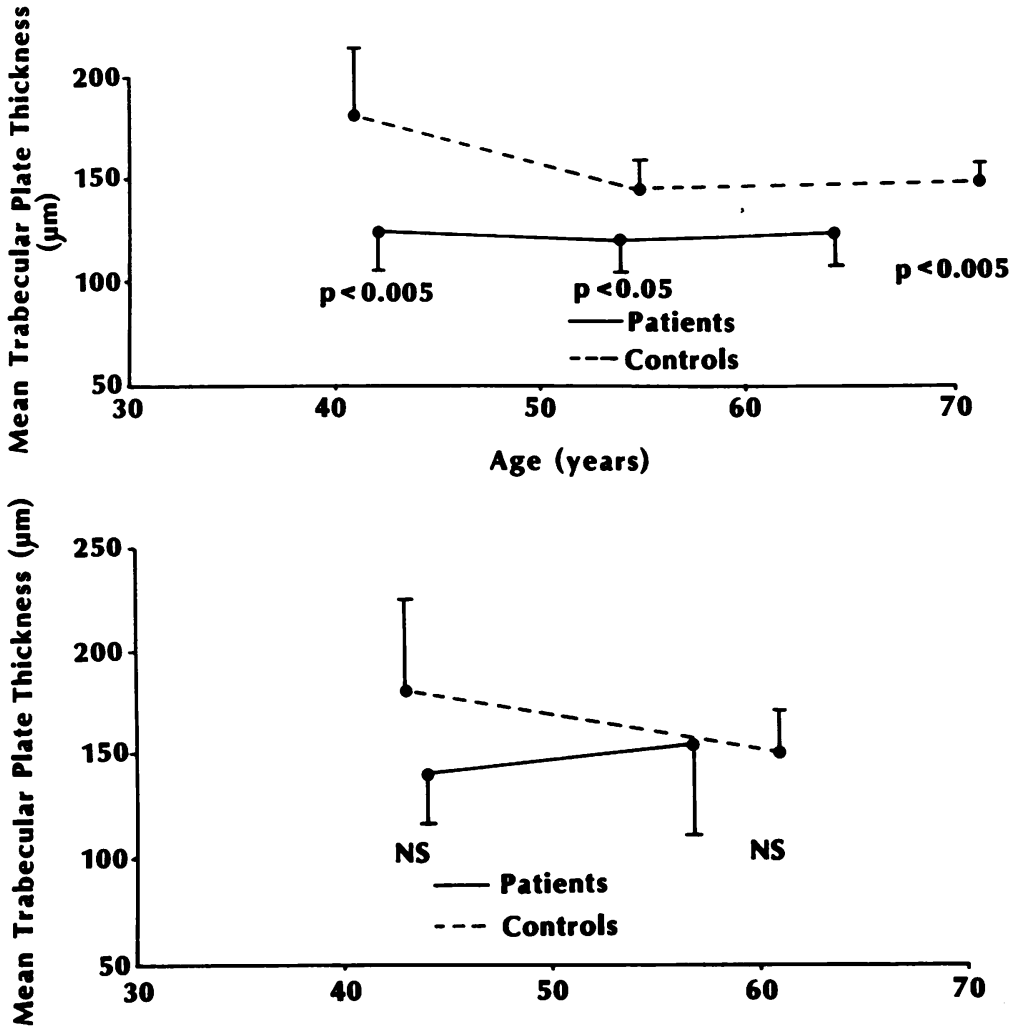

Fig. 3 Mean trabecular plate thickness $(\mu \mathrm{m})$ in female patients and controls. Each point represents the mean value (SD) for the age group.

Fig. 4 Mean trabecular plate thickness $(\mu \mathrm{m})$ in male patients and controls. Each point represents the mean value $(S D)$ for the age group.

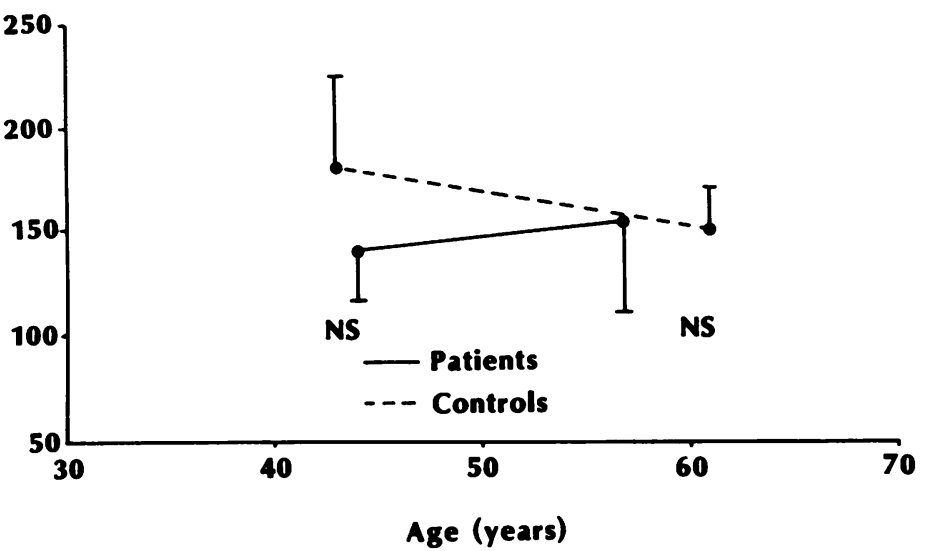

in the female patients in all age groups than in the controls $(p<0.005,0.05$, and 0.005$)$. Whereas in female controls the MTPS increased and MTPD decreased with age, values in the patients with rheumatoid arthritis showed no such change. The mean trabecular bone density in the 60-80 year old women was significantly higher in the patients than in the controls $(p<0 \cdot 001)$. The MTPT for the male patients was lower in the 34-50 year age group than in the controls, though this difference did not attain statistical significance. Values for MTPT in the older male age group were similar in patients and controls. No difference in MTPS or MTPD was observed between male patients and controls in either age group.

Regression analysis showed no significant correla- 
tion between bone histomorphometric indices and duration of disease or functional grading by the London method. ${ }^{17}$ There were significant correlations between the trabecular bone volume and MTPT $(r=0.625, p<0.001)$, MTPD $(r=0.589$, $\mathrm{p}<0 \cdot 001)$, and MTPS $(\mathrm{r}=-0.637, \mathrm{p}<0.001)$.

Two tailed $t$ tests and one way analysis of variance showed no significant correlation between any of the bone histomorphometric indices and second line drug therapy, intra-articular steroid therapy, or Steinbroker score. ${ }^{16}$

\section{Discussion}

These results show that iliac crest trabecular bone volume is reduced in non-steroid treated patients with rheumatoid arthritis and that this bone loss is due to trabecular thinning. The reduction in trabecular bone volume was only seen in the younger age groups of both sexes (34-50 and 50-60 years in women and 34-50 years in men), values in the most elderly age group in both sexes being similar to those in the controls. This suggests that rheumatoid arthritis is associated with premature bone loss, though total lifetime bone loss is similar to that seen in the normal aging population; longitudinal studies would be needed to confirm this. Reduced iliac crest trabecular bone volume in nonsteroid treated rheumatoid arthritis has not previously been reported, though two earlier studies also found a lower trabecular bone volume in biopsy specimens from patients with rheumatoid arthritis, some of whom were receiving steriod therapy. ${ }^{2021}$

The reduction in mean trabecular plate thickness followed a pattern similar to that seen for the trabecular bone volume, trabecular thinning being most prominent in the young patients. Under normal circumstances, age related bone loss is associated mainly with trabecular thinning in men, whereas in women the predominant mechanism appears to be erosion through and removal of trabeculae. ${ }^{22-24}$ In the male patients with rheumatoid arthritis the pattern of bone loss was thus similar to that observed in normal aging males, though trabecular thinning occurred at an earlier age. In the female patients, however, the normal structural changes accompanying age related bone loss were replaced by trabecular thinning, and the decrease in mean trabecular plate density and increase in mean trabecular plate separation that would normally be seen in older women were not observed. This suggests that some factor, related either directly or indirectly to the disease process, was able to over-ride the normal mechanisms of bone loss in women and to superimpose an alternative mechanism, namely trabecular thinning.
Although several studies have indicated that the prevalence of osteoporosis is increased in patients with rheumatoid arthritis, it is unclear whether this $\Rightarrow$ is solely due to disease related factors such as corticosteroid therapy and reduced physical activity? or whether the disease process has a direct effect on bone mass. In the present study only patients who $\frac{\bar{\sigma}}{\sigma}$

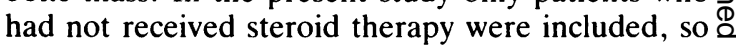

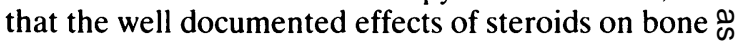
could be excluded, and we were unable to show any $\vec{\circ}$ relation between bone histomorphometric indices and assessments of functional ability. As bone loss is $\vec{\omega}$ a slow process, however, occurring over many years, any assessment of the effects of inactivity must take into account the duration of disease and its course $\vec{\sigma}$ over that time; functional assessments made at one point in time may not be representative of past $\vec{\infty}$ events nor do they necessarily reflect disease dura- $\mathscr{C}_{0}$ tion. Others have reported evidence that reduced physical activity is an important factor in the bone loss associated with rheumatoid arthritis. ${ }^{4}{ }^{10}$ Moreover, disease activity and duration, which are likely to be important determinants of functional $\stackrel{\Phi}{\rightrightarrows}$ ability, have been shown in some studies to be related to bone mass. Using a composite index of $\stackrel{\mathbb{D}}{\stackrel{D}{-}}$ disease activity, Reid et al found a weak, bôt $\overrightarrow{0}$ statistically significant correlation with total bod calcium in non-steroid treated patients ${ }^{8}$; others using single measurements of disease activity and localised skeletal measurements or radiology, have reported similar findings. ${ }^{9} 2526$ Attempts to correlate disease duration and bone mass have produced $\stackrel{\odot}{\Phi}$ conflicting results, some studies demonstrating a significant correlation, ${ }^{169}$ whereas others, includ-윽 ing the present study, have been unable to show any relationship. 42526

The cellular pathophysiology of bone loss in rheumatoid arthritis is unknown. Kinetic studies of $\frac{0}{2}$ bone turnover have generally shown reduced accre- $\overline{-}$ tion rates, supporting decreased bone formation in parts of the skeleton away from involved joints. ${ }^{27-29} 8$ This finding has not been universal, ${ }^{30}$ however, and Rosenspire et al reported increased skeletal uptake응 of ${ }^{99 \mathrm{~m}} \mathrm{Tc}$ pyrophosphate, indicating increased bone turnover ${ }^{31}$ Measurement of levels of serum osteo-을. calcin (a bone protein dependent on vitamin K), which are raised in high turnover bone disease, has? also produced conflicting results in patients with $\tilde{O}$ rheumatoid arthritis. Thus reduced levels, indicative N of decreased bone formation, have been reported ing three studies, ${ }^{29}{ }^{32}{ }^{33}$ but Gevers et al have recently reported increased levels. ${ }^{34}$ Increased alkaline phos- $-\frac{C}{\mathbb{D}}$ phatase levels, which may reflect increased bone $\stackrel{\Phi}{?}$ formation, are well recorded in rheumatoid 0 arthritis, ${ }^{67}$ but the relative contributions made by응 liver and bone isoenzymes have not been estab- $\mathbb{D}$ 
lished. Raised parathyroid hormone levels have also been reported in rheumatoid arthritis, ${ }^{35}$ though this finding has not been universal, ${ }^{36}$ especially when mid-region assays have been used. ${ }^{29}$

The most detailed bone histomorphometric study in rheumatoid arthritis to date is that of Duncan et $a l,{ }^{2}$ who examined indices of bone formation in rib biopsy specimens using tetracycline labelling. Although he interpreted his results as supporting increased resorption rather than decreased formation as the cause of bone loss, reduced tetracycline uptake and osteoid surface in three out of five and four out of seven patients respectively indicates a reduction in bone formation. The increase in resorption spaces found in all patients may thus have been due to failure, because of decreased bone formation, to fill in previously resorbed cavities rather than indicating an absolute increase in bone resorption. $\mathrm{Ng}$ et al, however, did not show any increase in the percentage of bone surface occupied by resorption cavities in their study of iliac crest biopsy specimens from patients with rheumatoid arthritis. ${ }^{20}$ Thus most of the evidence supports a role for decreased bone formation in osteoporosis associated with rheumatoid arthritis, but the possibility that increased bone resorption also contributes cannot be excluded.

The clinical significance of generalised bone loss associated with rheumatoid arthritis has not been established; although there is evidence that the risk of osteoporotic fracture is increased in corticosteroid treated patients with rheumatoid arthritis, no such evidence exists for those not receiving steroid therapy, and it is unclear at present whether prophylaxis or treatment is indicated in the latter group. If subsequent studies do show an increased risk of fracture, knowledge of the structural and cellular mechanisms of bone loss may provide a rationale for the choice of therapeutic agent. Thus if the major part played by decreased bone formation is confirmed, a drug which stimulates osteoblasts, such as sodium fluoride, would seem appropriate. This drug increases trabecular width and thus may be most effective when bone loss is associated with trabecular thinning rather than when erosion and removal of trabeculae has destroyed the normal trabecular bone structure. In addition to therapeutic implications, knowledge of the cellular pathophysiology of bone loss associated with rheumatoid arthritis may lead to a better understanding of direct and indirect disease related factors which affect bone in this condition.

This work was supported by the Arthritis and Rheumatism Council of Great Britain and by the Welsh Office. We are grateful to Dr R Newcombe for statistical advice and to Mr Ian Thomas for help with the statistical analysis. We also thank Dr J D Jessop for allowing us to study patients enrolled in the second line drug treatment trial.

\section{References}

1 McConkey B, Fraser G M. Bligh A S. Transparent skin and osteoporosis. Ann Rheum Dis 1965: 24: 210-23.

2 Duncan H. Frost H M. Villanueva A R. Sigler J W. The osteoporosis of rheumatoid arthritis. Arthritis Rheum 1965; 8: 943-54.

3 Saville P D. Kharmosh O. Osteoporosis of rheumatoid arthritis: influence of age, sex and corticosteroids. Arthritis Rheum 1967; 10: 423-30.

4 Bjelle H O, Nilsson B E. Osteoporosis in rheumatoid arthritis. Calcified Tissue Research 1970: 5: 327-32.

5 Mueller M N, Jurist J M. Skeletal status in rheumatoid arthritis: a preliminary report. Arthritis Rheum 1973; 16: 66-70.

6 Kennedy A C. Lindsay R. Bone involvement in rheumatoid arthritis. Clin Rheum Dis 1977; 3: 403-20.

7 Als O S. Christiansen C. Hellensen C. Prevalence of decreased bone mass in rheumatoid arthritis. Relation to antiinflammatory treatment. Clin Rheumatol 1984: 3: 201-8.

8 Reid D M, Kennedy N S J, Smith M A. Tothill P. Nuki G. Total body calcium in rheumatoid arthritis: effects of disease activity and corticosteroid treatment. Br Med J 1982; 285: 330-2.

9 Hancock D A. Asiedu-Offei S. Atkinson P J. Reed G W. Wright V. Femoral bone mass in patients with rheumatoid arthritis and osteo-arthrosis. Rheumatol Rehabil 1978; 17: 65-71.

10 Castillo B A. El Sallab R A. Scott J T. Physical activity, cystic erosions and osteoporosis in rheumatoid arthritis. Ann Rheum Dis 1965: 24: 522-6.

11 Hooyman J R, Melton L J, Nelson A M. O'Fallon W M. Riggs B L. Fractures after rheumatoid arthritis. A population-based study. Arthritis Rheum 1984; 27: 1353-61.

12 Verstraeten A. Dequeker J. Vertebral and peripheral bone mineral content and fracture incidence in post-menopausal patients with rheumatoid arthritis: effect of low dose corticosteroids. Ann Rheum Dis 1986; 45: 852-7.

13 Kleerekoper M, Villanueva A R. Stanciu J, Rao D S, Parfitt A $\mathrm{M}$. The role of three-dimensional trabecular microstructure in the pathogenesis of vertebral compression fractures. Calcif Tissue Int 1985: 37: 574-7.

14 Parfitt A M, Matthews C H E. Villanueva A R, Kleerekoper M. Frame B. Rao D S. Relationships between surface volume and thickness of iliac trabecular bone in ageing and in osteoporosis. J Clin Invest 1983; 72: 1396-409.

15 Ropes M W, Bennett G A, Cobb S, Jacox R, Jessar R A. Proposed diagnostic criteria for rheumatoid arthritis. Bull Rheum Dis 1956; 7: 121-4.

16 Steinbroker O, Traeger C H. Batterman E C. Therapeutic criteria in rheumatoid arthritis. JAMA 1949; 140: 659-62.

17 Kirwan J R. Reebach J S. Using a modified Stamford health assessment questionnaire to assess disability in UK patients with RA [Abstract]. Proceedings of the Heberden Society AGM. London. 1982; 22.

18 Vedi S. Compston J E. Webb A. Tighe J R. Histomorphometric analysis of bone biopsies from the iliac crest of normal British subjects. Bone 1982; 4: 231-6.

19 Garrahan N J, Mellish R W E, Vedi S, Compston J E. Measurement of mean trabecular plate thickness by a new computerised method. Bone (in press).

$20 \mathrm{Ng} \mathrm{K} \mathrm{C,} \mathrm{Revell} \mathrm{P} \mathrm{A,} \mathrm{Beer} \mathrm{M,} \mathrm{Boucher} \mathrm{B} \mathrm{J,} \mathrm{Cohen} \mathrm{R} \mathrm{D.} \mathrm{Currey}$ H L F. Incidence of metabolic bone disease in rheumatoid arthritis. Ann Rheum Dis 1984; 43: 370-7.

21 Wordsworth B P. Vipond S, Woods C G, Mowat A G. Metabolic bone disease among in-patients with rheumatoid arthritis. Br J Rheumatol 1984; 23: 251-7.

22 Wakamatsu E, Sissons H A. The cancellous bone of the iliac crest. Calcified Tissue Research 1969; 4: 147-61.

23 Aaron J E, Makins N B, Sagreiya K. The microanatomy of trabecular bone loss in normal ageing men and women. Clin Orthop 1987; 215: 260-71. 


\section{Mellish, O'Sullivan, Garrahan, Compston}

24 Compston J E, Mellish R W E, Garrahan N J. Age-related changes in iliac crest trabecular microanatomic bone structure in man. Bone (in press).

25 Oka M, Rekonen A. Kuikka J, Anttinen J. Bone mineral density in rheumatoid arthritis measured by the gamma transmission method. Scand J Rheumatol 1975; 4: 28-32.

26 Virtama P. Helela T. Kalliomaki J L. Osteoporosis in rheumatoid arthritis. Acta Rheumatol Scand 1968: 14: 276-84.

27 Dymling J F. Calcium kinetics in osteopenia and parathyroid disease. Acta Med Scand 1964: 175: (suppl 408): 16-18.

28 Heaney R P. Walch J J, Steffes P. Skillman T G. Periarticular bone remodelling in rheumatoid arthritis. Calcified Tissue Research 1968; (suppl): 33-33B.

29 Sambrook P N, Ansell B M. Foster S et al. Bone turnover in early rheumatoid arthritis. 1. Biochemical and kinetic indexes. Ann Rheum Dis 1985: 44: 575-9.

30 Bergmann P, Mannicourt D, Martin P, Orleff S, Schoutens A. Regional bone calcium turnover rate in rheumatoid arthritis: comparison with disease activity. Adv Inflamm Res 1982; 3: 303-12.
31 Rosenspire K C. Kennedy A C. Steinbach J. Blau M. Green $\mathrm{F} A$. Investigation of the metabolic activity of bone in $\mathrm{s}$ rheumatoid arthritis. J Rheumatol 1980; 7: 469-73.

32 Orth R W. Weisman M H. Catherwood B D. Manolagas S C. Deftos L J. Bone loss in rheumatoid arthritis. Arthritis Rheum1983: 26 (suppl 4): Abs 100.

33 Riis B J. Als O S. Christiansen C, Catherwood B D. Deftos L J Bone turnover in rheumatoid arthritis. Calcif Tissue Int 1984: 36 (suppl 2): S4.

34 Gevers G. Devos P. DeRoo M. Dequeker J. Increased levels of osteocalcin (serum bone GLA-protein) in rheumatoid arthritis. Br J Rheumatol 1986: 25: 260-2.

35 Kennedy A C. Allam B F. Boyle I T, Nuki G. Rooney P J. Buchanan W W. Abnormalities of mineral metabolism sugges- $\vec{\omega}$ tive of parathyroid overactivity in rheumatoid arthritis. Curr Med Res Opin 1975; 3: 345-8.

36 Verstracten A. Guesens P. Dequeker J, Bouillon R. Bone metabolism in rheumatoid arthritis. Calcif Tissue Int 1983: 35 के (suppl): Abs 235 . 